\title{
ACCELERATION OF ELECTRON BUNCHES USING PERIODIC DIELECTRIC STRUCTURES WITH AND WITHOUT COATING
}

\author{
A.V. Vasyliev, A.O. Bolshov, K.V. Galaydych, A.I. Povrozin, G.V. Sotnikov \\ National Science Center "Kharkov Institute of Physics and Technology”, Kharkiv, Ukraine \\ E-mail: vasilyev.andrey90@gmail.com
}

The numerical studies of high acceleration gradients obtaining for the dielectric laser accelerators (DLA) based on-chip structures with one-sided laser excitation at a wavelength of $800 \mathrm{~nm}$ are presented. The electron flight heights of 200 and $400 \mathrm{~nm}$ over a structure are presented. The influence of the geometric parameters of the structures on the acceleration gradients was also investigated. A study of changes in the acceleration gradients of structures, when applying a gold coating on these types of structures, has been carried out.

PACS: 41.75.Jv, 41.75.Ht, 42.25.Bs

\section{INTRODUCTION}

Today, laser accelerators are given an increasing place in research practice, along with the development of laser-plasma accelerators [1], a special niche is occupied by the development of accelerators based on-chip structures [2 - 4]. For the accelerators based on CHIP structures, two directions are relevant. The first is obtaining a maximum acceleration efficiency (with a maximum devices miniaturization), and the second is its optimization for this type of accelerator production for the fundamental and applied studies. Recent experimental studies on the acceleration of sub-relativistic [3, 4], as well as relativistic electrons [2] on CHIP structures, have served as the beginning for the further comprehensive development of this direction.

DLA works by stimulated laser an electric modefield excitation with a nonzero electrical component, parallel to the electron velocity. For synchronous interaction over long distances, the phase velocity of the excited mode should be equal to an electron velocity. Near-field modes are efficiently excited by a laser overthe dielectric periodic structures of various geometries. A change in the geometry of periodic structures leads to a change in the acceleration gradients of charged particles.

Several early proposals were based on the use of reflective (all-metal) diffraction gratings [5 - 7]. The acceleration mechanism used in these demonstrations was the opposite of the Smith-Purcell effect [8]. The earliest proposal for a stepped DLA based on a periodic nanostructure $[9,10]$ describes a design that used absorbing thin metal gratings deposited on flat dielectric surfaces.

In our work, we investigate dielectric chip structures of various profiles, including those with a metal coating deposited on them, to assess the possibility of obtaining the highest gradient of electron acceleration.

A general principle of acceleration can be demonstrated (Fig. 1) using a rectangular CHIP structure used at the SLAC [4].

An electron moves along a periodic CHIP structure from left to right. A laser excites a longitudinal component of an electric field in the structure, falling perpendicular to its surface from below. The CHIP structure forms an inhomogeneous electric field along the surface, which changes its directionality with a period equal to half the laser wavelength.

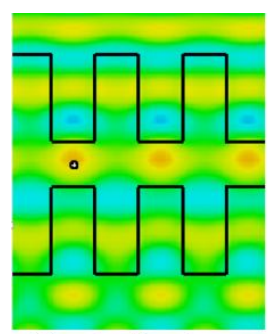

a)Accelerating phase

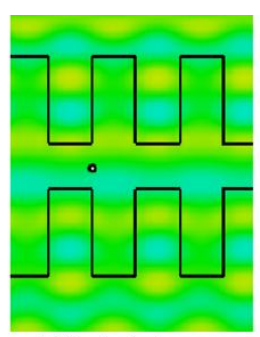

b)Neutral phase

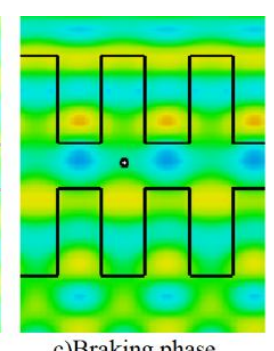

c)Braking phase
Fig. 1. A general principle of the acceleration of the relativistic electrons in a CHIP structure. A period of the structure is equal to a laser wavelength

Acceleration occurs at the moment when the electron is in the accelerating field above the "pillar" of the lattice Fig. 1,a. After a quarter of a period, a neutral phase appears in the structure, when the moment of a change in the direction of the electric field occurs (see Fig. 1,b). After another quarter of the period, at the moment when the electric field on the structure is directed in the opposite direction, the electron is in the drift space.

Under the condition of radiation incidence perpendicular to the plane of the grating and its lines, the acceleration of particles will occur along the surface of the grating also perpendicular to its lines [2]. Let's conventionally denote $\mathrm{x}$-coordinate along the lattice lines and perpendicular to the motion of particles; $y$ is the coordinate perpendicular to the lattice surface, and $\mathrm{z}$ is along the direction of particle motion. For the condition of synchronization of the electron velocity with the phase velocity of the exciting wave, one can use [3]:

$$
\lambda_{p}=n \beta \lambda,
$$

where $n$ is the mode of the electromagnetic field excited by the incident wave; $\beta=v / s$ is the dimensionless speed, $v$ is the speed of electrons, $\mathrm{c}$ is the speed of light; $\lambda$ is the wavelength of the exciting laser radiation.

For the simplicity, we assume that the structure is excited from one side with a Gaussian laser pulse. When choosing the initial simulation parameters: the duration of the laser pulse and the electron beam, we were guided by our previous studies [11] and the parameters used at SLAC, i. e. $\Lambda=800 \mathrm{~nm}, \tau=120 \mathrm{fs}, \beta=0.9995$, initial electron energy $\mathrm{E}=50 \mathrm{MeV}$, beam diameter is $50 \mu \mathrm{m}$, bunch chargeis $10^{-17 \circ} \mathrm{C}$, bunch duration is $0.35 \mathrm{fs}$. 
The results of the numerical studies on acceleration processes modeling in periodic structures of various profiles with and without deposition under their excitation by a Gaussian beam are presented below.

\section{SIMULATION RESULTS}

The Gaussian beam allows us to get the simulation results that are close to a real experiment. Its electric field can be represented as follows

$$
\begin{aligned}
& E(r, z, t)=E \frac{w_{0}}{p(z)} \exp \left[-\frac{r^{2}}{w^{2}(z)}\right] \exp \left[-2 \ln (2) \frac{(z-c t)^{2}}{c^{2} \tau_{0}^{2}}\right] \\
& \times \mathfrak{R}\left\{\exp \left[i \omega_{0} t-i k_{0} z-i k_{0} \frac{r^{2}}{2 R(z)}+i \psi_{g}(z)\right]\right\},
\end{aligned}
$$

where $E_{p}$ is an amplitude of the electric field; $w_{0}$ is a waist or the smallest transverse size of the laser in the focal plane $(z=0) ; c$ is a speed of light; $\tau_{0}$ is full width at half maximum of the pulse duration; $k_{0}=2 \pi / \lambda_{0}$ and $\omega_{0}=c k_{0}$ represent the wave number and angular frequency of the laser beam with the wavelength $\lambda_{0}$ respectively. The propagation of a Gaussian laser pulse is completely characterized by the beam waist $w(z)$, the radius of curvature of the wave front $R(z)$, and the Guy phase shift $\psi_{g}(z)$ as the function of $z$,

$$
\begin{gathered}
w(z)=w_{0} \sqrt{1+\left(\frac{z}{z_{R}}\right)^{2}} ; R(z)=z\left[1+\left(\frac{z}{z_{R}}\right)^{2}\right] ; \\
\psi_{g}(z)=\arctan \left(\frac{z}{z_{R}}\right),
\end{gathered}
$$

where $z_{R}=\pi w_{0}^{2} / \lambda_{0}$ is the Rayleigh length, which represents the position at which the transverse area of the laser beam is doubled compared to the area in the focal plane due to difraction.

The laser beam with $w_{0}=10 \mu \mathrm{m}$ was focused on the surface of the chip structure.

Fig. 2 shows the types of profiles of CHIP-structures that were used in the numerical simulation.

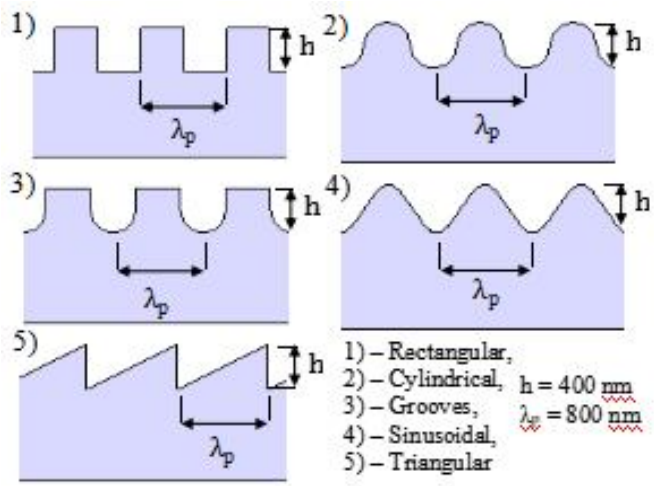

Fig. 2. The different profiles of the periodic CHIP-structures under investigation

A height of the pillar in all cases was $h=400 \mathrm{~nm}$. A width of the tooth for all cases, except for the triangular profile, was also $400 \mathrm{~nm}$.
The motivation for the choice of the profiles of CHIP structures considered here was that the types of profiles 3, 4, 5 (see Fig. 2) are available for use, since their industrial production in quality has been established as the diffraction gratings. Profile 1 is used in real experiments at laboratories [ 1 - 4], and profile 2 is easy to produce by etching.

At all stages of modeling, structures with a length of $L=16 \mu \mathrm{m}$ were used, which is 20 optical periods of the wavelength.

\subsection{SIMULATION OF ACCELERATION USING UNCOATED STRUCTURES}

The structure was excited by the Gaussian pulse with an electric field amplitude $E_{p}=10^{9} \mathrm{~V} / \mathrm{m}$. The pulse fell perpendicularly from the side of the structure substrate. The accelerated electrons had an initial input energy of $50 \mathrm{MeV}$. Simulation was carried out for two different flight heights over the structure, $\Delta y=200 \mathrm{~nm}$ and $\Delta \mathrm{y}=400 \mathrm{~nm}$.

Simulations were also performed for relativistic electrons with an initial energy of $2.1 \mathrm{MeV}$. this case is also shown in the graph in Figs. 3, 2 (red curve).

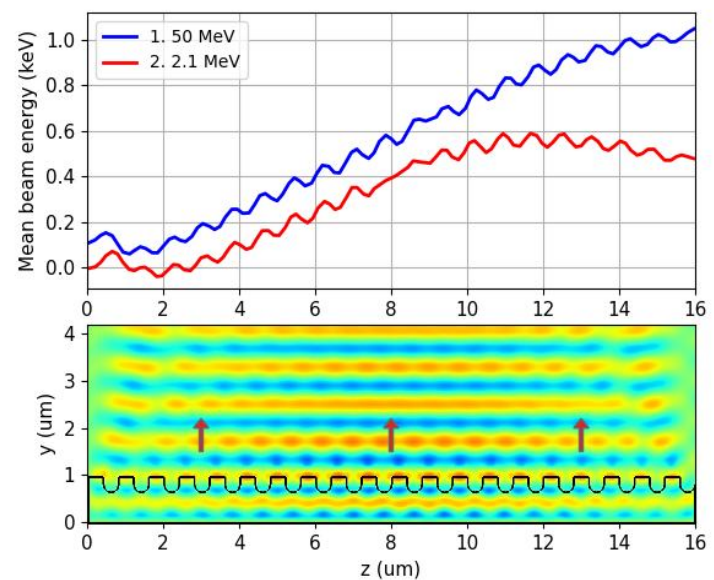

Fig. 3. A longitudinal electric field distribution at fixed moment of time, excited by the Gaussian wave over the grooves structure and an increase in the electron energy gain at $\Delta y=400 \mathrm{~nm}$. Energy of electrons:

1 -blue curve, $50 \mathrm{MeV} ; 2$ - red curve, $20 \mathrm{MeV}$

Fig. 3 demonstrates the distribution of the electric field over the structure at a fixed moment of time, excited by a Gaussian beam (direction shown by arrows) and formed by a structure with a geometric profile (grooves). The blue curve in the graph shows the average increase in the energy of electrons with an initial energy of $50 \mathrm{MeV}$, which are in the optimal accelerating phase.

Electrons with an initial energy of $2.1 \mathrm{MeV}$ (red curve) in Fig. 3 are subject to the effect of desynchronization of the phase velocity of the wave with the electron velocity, compared to the case for $50 \mathrm{MeV}$ (see Fig. 3, 1). This is characterized by an energy decrease, indicated by the curve bend. In turn, this indicates the need to comply with the conditions from the expression (1).

Fig. 4 shows the graphs of changes in the average energy gain of electron beams at $\Delta y=400 \mathrm{~nm}$ for various profiles of the structures. The graphs clearly show how the energy changes for each type of structure. It is also seen that the structure with a grooves profile has the 
maximum increase in electron energy. The data from the simulation experiments are summarized in Table 1.

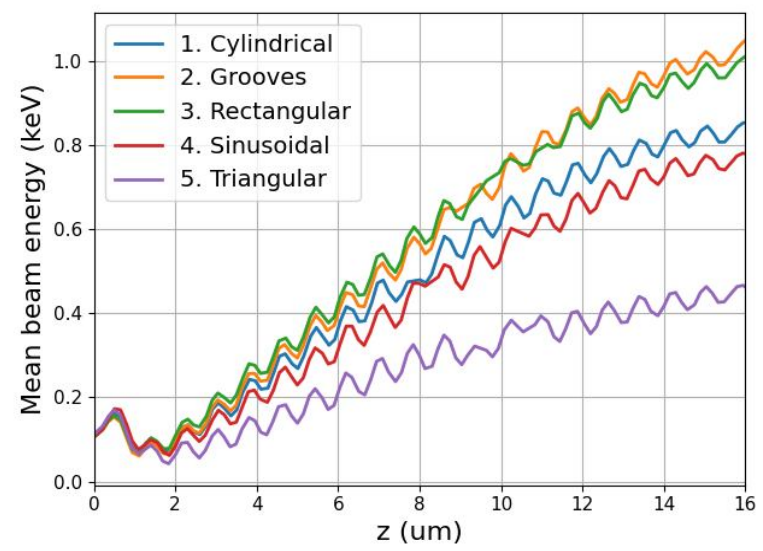

Fig. 4. Mean energy of an electron beam for the various types of the structures

Table 1

Acceleration gradients for the different profiles of the uncoated structures

\begin{tabular}{|c|c|c|}
\hline Structure type & $\begin{array}{c}\text { Acceleration } \\
\text { gradient } \\
\text { at } \Delta y=200 \mathrm{~nm}, \\
\mathrm{MeV} / \mathrm{m}\end{array}$ & $\begin{array}{c}\text { Acceleration } \\
\text { gradient } \\
\text { at } \Delta \mathrm{y}=400 \mathrm{~nm}, \\
\mathrm{MeV} / \mathrm{m}\end{array}$ \\
\hline Rectangular & 64.63 & 60.75 \\
\hline Cylindrical & 55.19 & 51.94 \\
\hline Grooves & 66.44 & 62.50 \\
\hline Sinusoidal & 47.25 & 44.38 \\
\hline Triangular & 25.63 & 25.63 \\
\hline
\end{tabular}

Table 1 shows the results of the acceleration gradients of the electron beam at a flight height $\Delta y$ equal to 200 and $400 \mathrm{~nm}$, obtained by modeling, for each of the structures under consideration. It can be seen that at a flight height of $400 \mathrm{~nm}$, the acceleration gradient is approximately $7 \%$ less than at a height of $200 \mathrm{~nm}$. A better accelerating gradient, obtained as the results of simulations, is provided by the groove structure.
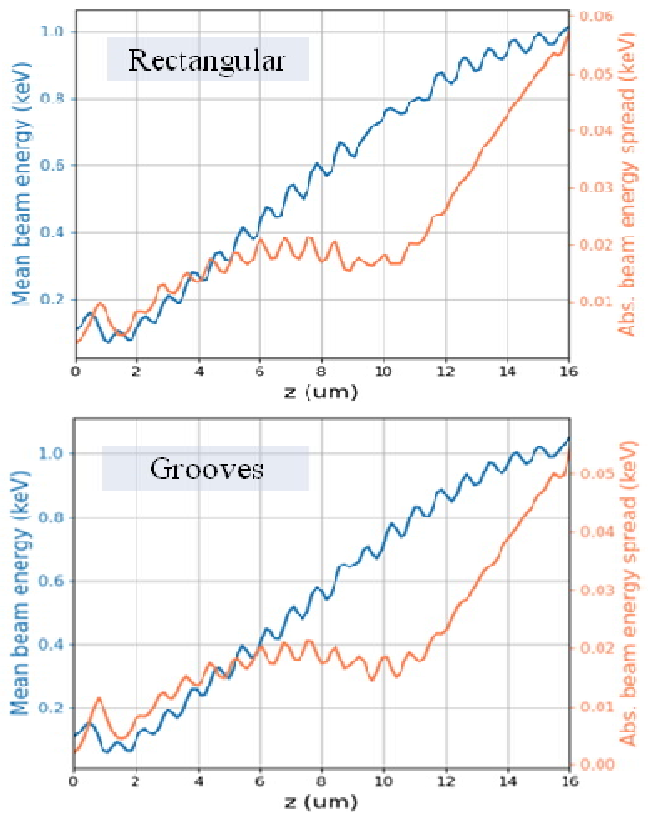

Fig. 5. Energy gain of electrons and abs. beam energy spread of the electron bunch for the rectangular and grooves structures
Fig. 5 illustrates shows the graphs of changes in the average beam energy and the beam energy spread for the currently most popular rectangular structure [1 - 4], and the grooves structure, which showed the best results in modeling. The graphs show results that are close in value. This demonstrates the possibility of using easierto-manufacture groove structures for acceleration experiments.

\subsection{SIMULATION OF ACCELERATION USING GOLD-PLATED STRUCTURES}

To carry out these experiments, we simulated a $200 \mathrm{~nm}$ thick gold layer deposited on the working surface of the structures. The structures were excited by a Gaussian pulse with an electric field strength $E_{p}=$ $10^{9} \mathrm{~V} / \mathrm{m}$, the pulse was incident perpendicular to the coated side of the structure. The accelerated electrons had initial input energy of $50 \mathrm{MeV}$; the simulation was carried out for two different heights of flight over the structure, namely 200 and $400 \mathrm{~nm}$.
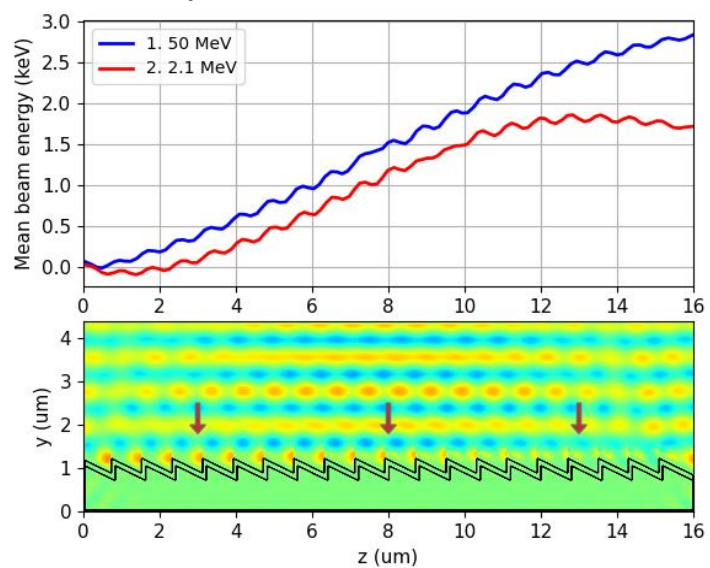

Fig. 6. A longitudinal electric field distribution at fixed moment of time, excited by a Gaussian pulse over a triangular structure and the electron energy gain at $\Delta y=400 \mathrm{~nm}$. The energy of electrons:

1. blue curve $-50 \mathrm{MeV}$; 2. red curve - $20 \mathrm{MeV}$

Fig. 6 shows the distribution of the electric field at a fixed moment of time, excited by a Gaussian beam over a structure with a triangular profile. The blue curve in the graph shows the change of energy gain of electrons with initial input energy of $50 \mathrm{MeV}$, which are in the optimal accelerating phase. A significant increase in energy can be observed compared to the previous experiment (see Fig. 4).

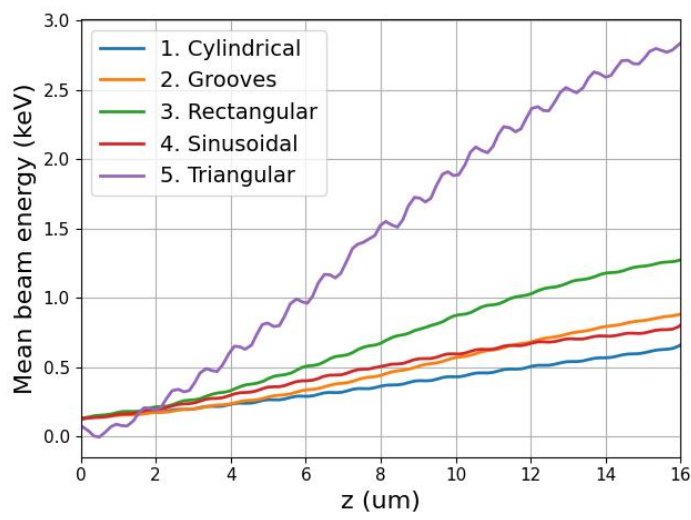

Fig. 7. Mean energy of an electron beam for the various types of structures with gold coating 
Also, as in the previous experiment, we can observe the effect of the desynchronization for electrons with an initial energy of $2.1 \mathrm{MeV}$, which is shown by the red curve.

Fig. 7 demonstrates the changes of energy gain of electron beams at $\Delta y=400$ for various profiles with a deposited gold coating. A structure with a triangular profile with a coarse increase in energy along with the rest of the structures. The data from the simulation experiments are presented in Table 2.

Acceleration gradients for different profiles

Table 2 of gold-plated structures

\begin{tabular}{|c|c|c|}
\hline Structure type & $\begin{array}{c}\text { Acceleration } \\
\text { gradient } \\
\text { at } \Delta \mathrm{y}=200 \mathrm{~nm}, \\
\mathrm{MeV} / \mathrm{m}\end{array}$ & $\begin{array}{c}\text { Acceleration } \\
\text { gradient } \\
\text { at } \Delta \mathrm{y}=400 \mathrm{~nm} \\
\mathrm{MeV} / \mathrm{m}\end{array}$ \\
\hline Rectangular & 87.50 & 74.81 \\
\hline Cylindrical & 46.88 & 35.00 \\
\hline Grooves & 57.50 & 49.38 \\
\hline Sinusoidal & 59.38 & 42.25 \\
\hline Triangular & 208.13 & 183.75 \\
\hline
\end{tabular}

Table 2 shows the results of the electron beam acceleration gradients obtained by simulation for heights of $\Delta y=200 \mathrm{~nm}$ and $\Delta y=400 \mathrm{~nm}$, for each type of structure. It can be seen from the results that an increase in the height $\Delta y$ the acceleration gradient decreases by approximately $14 \%$. It can also be seen a significant difference in the acceleration gradient for the triangular structure. We suppose that this is due to the interference of laser radiation caused by the shape of the structure profile.
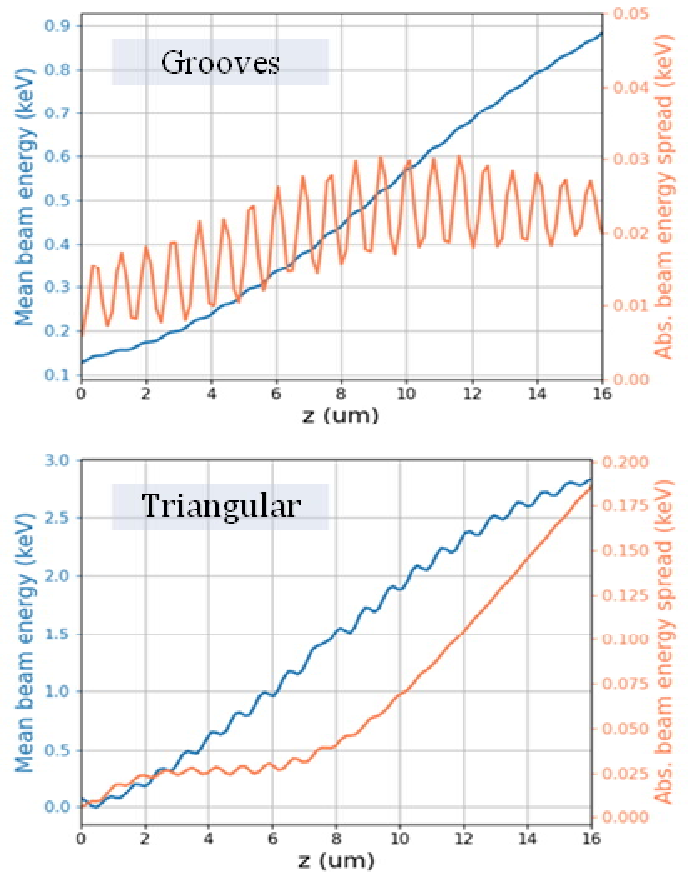

Fig. 8. Energy gain of electrons and abs. beam energy spread, of the electron bunch for rectangular and grooves structures

Fig. 8 shows the graphs of the change of the average beam energy and the beam energy spread for the triangular structure, which proved to be the favorite and the structure of the grooves. We can note that the high acISSN 1562-6016. BAHT. 2021. № 4(134) celeration gradient in the triangular structure increased the spread of electron beam energies by almost an order of magnitude. A comparison of the obtained data is presented in Table 3.

Table 3

$A$ ratio of acceleration gradients obtained for gold-plated structures to acceleration gradients for uncoated structures

\begin{tabular}{|c|c|c|}
\hline $\begin{array}{c}\text { With coating/without } \\
\text { coating }\end{array}$ & $\Delta \mathrm{y}=200 \mathrm{~nm}$ & $\Delta \mathrm{y}=400 \mathrm{~nm}$ \\
\hline Rectangular & 1.35 & 1.23 \\
\hline Cylindrical & 0.85 & 0.67 \\
\hline Grooves & 0.86 & 0.79 \\
\hline Sinusoidal & 1.25 & 0.95 \\
\hline Triangular & 8.12 & 7.16 \\
\hline
\end{tabular}

Table 3 shows a ratio of acceleration gradient obtained for gold-plated structures to acceleration gradients for uncoated structures. We can evaluate the effect of the applied coating on the acceleration gradient for each specific case. The best coating result can be get with the triangular structure. The acceleration gradient for this case increased more than 8 times.

\section{CONCLUSIONS}

The values of the accelerating gradients for the chip structures of various profiles and for conditions that are close to real experiments are obtained.

The groove structure gave the maximal accelerating gradient for the case of the uncoated structure.

The gold plating can either increase or decrease the accelerating gradient depending on the particular profile geometry.

The maximal acceleration gradient of $208 \mathrm{MeV} / \mathrm{m}$ was obtained for the triangular structure, which is 2.5 times higher than for acceleration on the structure with the rectangular profile. A practical value of the obtained results is due to the possibility of carrying out the experiments using industrially manufactured diffraction gratings.

Based on the obtained results, further studies are planned to be done for the experiments with gold-coated chip structures, including those with the orientation of the exciting laser radiation at different angles.

\section{ACKNOWLEDGEMENTS}

Work supported by The National Research Foundation of Ukraine, program "Leading and Young Scientists Research Support" (project \# 2020.02/0299).

\section{REFERENCES}

1. ACHIP website: https://achip.stanford.edu

2. E.A. Peralta et al. Demonstration of electron acceleration in a laser-driven dielectric microstructure // Nature. 2013, № 503, p. 91-94.

3. J. Breuer and P. Hommelhoff. Laser-Based Acceleration of Nonrelativistic Electrons at a Dielectric Structure // Phys. Rev. Lett. 2013, v. 111, p. 134803.

4. K.J. Leedle et al. Laser acceleration and deflection of $96.3 \mathrm{keV}$ electrons with a silicon dielectric structure // Optics Letters. 2015, № 40, p. 18.

5. R.B. Palmer. A Laser-Drven Grating Linac // Paricle Accelartors. 1980, v. 11, p. 81-90. 
6. Y. Takeda and I. Matsui. Laser linac with grating // Nucl. Instrum. Methods. 1968, № 62, p. 306.

7. K. Mizuno, S. Ono, and O. Shimoe. Interaction between coherent light waves and free electrons with a reflection grating // Nature. 1975, № 253, p. 184.

8. K. Mizuno et al. Experimental evidence of the inverse Smith-Purcell effect // Nature. 1987, № 328, p. 45 .

9. A.W. Lohmann. Particle Accelerator Utilizing Coherent Light: U.S. Patent 3267383, issued 16th August 1966 .
10. A.W. Lohmann. Particle Accelerator: Canadian Patent 773768, Issued 12th December 1967.

11. A.V. Vasyliev, O. Bolshov, K. Galaydych, A. Povrozin, G.V. Sotnikov. Influence of the profile of the dielectric structure on the electric fields excited by a laser in dielectric accelerators based on-chip // Proc. 13th Int. Conf. on Accelerator and Large Experimental Physics Control Systems (ICALEPCS'11), Grenoble, France, 2021, paper IDTUPAB247. pdf.

Article received 22.06.2021

\section{УСКОРЕНИЕ ЭЛЕКТРОННЫХ СГУСТКОВ С ИСПОЛЬЗОВАНИЕМ ПЕРИОДИЧЕСКИХ ДИЭЛЕКТРИЧЕСКИХ СТРУКТУР С ПОКРЫТИЕМ И БЕЗ}

\section{А.В. Васильев, А.О. Больщов, К.В. Галайдыч, А.И. Поврозин, Г.В. Сотников}

Представлено исследование темпов ускорения методом численного моделирования для диэлектрических лазерных ускорителей на ЧИП-структурах с односторонним лазерным возбуждением на длине волны 800 нм. Расстояние пучка электронов 200 и 400 нм. Также исследовано влияние геометрических параметров структур на темпы ускорения. Проведено исследование изменения градиентов ускорения структур, при нанесении золотого покрытия на данные типы структур.

\section{ПРИСКОРЕННЯ ЕЛЕКТРОННИХ ЗГУСТКІВ 3 ВИКОРИСТАННЯМ ПЕРІОДИЧНИХ ДІЕЛЕКТРИЧНИХ СТРУКТУР 3 ПОКРИТТЯМ ТА БЕЗ}

\section{А.В. Васільєв, А.О. Большов, К.В. Галайдич, А.І. Поврозін, Г.В. Сотніков}

Представлено дослідження темпів прискорення методом чисельного моделювання для діелектричних лазерних прискорювачів на ЧІП-структурах із одностороннім лазерним збудженням на довжині хвилі 800 нм. Відстань пучка електронів 200 та 400 нм. Також досліджено вплив геометричних параметрів структур на темпи прискорення. Проведено дослідження зміни градієнтів прискорення структур при нанесенні золотого покриття на дані типи структур. 